\title{
Examining the North Atlantic Oscillation, East Atlantic Pattern, and Jet Variability since 1685
}

\author{
JAVIER MELLADO-CANO \\ Instituto Dom Luiz, Faculdade de Ciências, Universidade de Lisboa, Lisbon, Portugal, and Departamento de Física de la \\ Tierra y Astrofísica, Facultad de Ciencias Físicas, Universidad Complutense de Madrid, Madrid, Spain \\ DAVID BARRIOPEDRO \\ Instituto de Geociencias, Consejo Superior de Investigaciones Científicas, Universidad Complutense de Madrid, Madrid, Spain

\section{RICARDO GARCÍA-HERRERA} \\ Instituto de Geociencias, Consejo Superior de Investigaciones Científicas, and Departamento de Física de la Tierra y Astrofísica, \\ Facultad de Ciencias Físicas, Universidad Complutense de Madrid, Madrid, Spain

\section{RICARDO M. TRIGO} \\ Instituto Dom Luiz, Faculdade de Ciências, Universidade de Lisboa, Lisbon, Portugal
}

\section{ARMAND HERNÁNDEZ}

Institute of Earth Sciences Jaume Almera, Consejo Superior de Investigaciones Científicas, Barcelona, Spain

(Manuscript received 18 February 2019, in final form 20 June 2019)

\begin{abstract}
Recent studies have stressed the key role of the east Atlantic (EA) pattern and its interactions with the North Atlantic Oscillation (NAO) in Euro-Atlantic climate variability. However, instrumental records of these leading patterns of variability are short, hampering a proper characterization of the atmospheric circulation beyond the mid-nineteenth century. In this work, we present the longest (1685-2014) observationalbased records of winter NAO and EA indices as well as estimates of the North Atlantic eddy-driven jet stream speed and latitude for the same period. The time series display large variability from interannual to multidecadal time scales, with, for example, positive (negative) EA (NAO) phases dominating before 1750 (during much of the nineteenth century). By identifying winters with different combinations of NAO/EA phases in the twentieth century, our results highlight the additional role of EA in shaping the North Atlantic action centers and the European climate responses to NAO. The EA interference with the NAO signal is stronger in precipitation than in temperature and affects areas with strong responses to NAO such as Greenland and the western Mediterranean, which prevents simplistic relationships of natural proxies with NAO. The last three centuries uncover multidecadal periods dominated by specific NAO/EA states and substantial interannual-tocentennial variability in the North Atlantic jet stream, thus providing new evidence of the dynamics behind some outstanding periods. Transitions in the NAO/EA phase space have been recurrent and pin down longlasting anomalies, such as the displacement of the North Atlantic action centers in the late twentieth century, besides some disagreements between NAO indices.
\end{abstract}

\section{Introduction}

The North Atlantic eddy-driven jet stream governs the atmospheric circulation in the Euro-Atlantic sector and has a mediating role between the large-scale patterns of

Corresponding author: Javier Mellado-Cano, jmellado@ucm.es atmospheric variability, synoptic weather regimes, and ultimately regional climates. The North Atlantic Oscillation (NAO) is the main pattern of atmospheric variability in the Euro-Atlantic sector (e.g., Pinto and Raible 2012, and references therein). With the exception of the high summer (July-August; Folland et al. 2009), the spatial pattern of the NAO is characterized by a meridional 
dipole in the pressure field between the Azores high and Icelandic low, also referred to as the North Atlantic action centers. Positive phases of the NAO are associated with warm and wet conditions in central and northern Europe as well as precipitation deficits in southern Europe, while the opposite pattern is observed during negative phases (e.g., Trigo et al. 2002). However, climatic anomalies in other European regions are not properly accounted for by the NAO (e.g., García-Herrera and Barriopedro 2018, and references therein). Besides the NAO, other largescale patterns of atmospheric circulation variability are also known to play a significant role in the European climate, particularly the east Atlantic (EA) and Scandinavian (SCAND) patterns (Comas-Bru and McDermott 2014; Jerez and Trigo 2013; Trigo et al. 2008). In addition, previous studies have shown that the NAO signal in surface climate cannot be considered stationary (e.g., Vicente-Serrano and López-Moreno 2008; Raible et al. 2014). Sources of nonstationary NAO signals include migrations and intensity changes in the North Atlantic action centers (e.g., Barriopedro et al. 2014; Comas-Bru and McDermott 2014). These limitations to characterize the European climate variability can be partially overcome by complementing the NAO with other patterns of variability.

The second pattern of climate variability in the region is the EA pattern (Wallace and Gutzler 1981; Barnston and Livezey 1987) traditionally described as a dipole in the pressure field, whose centers of variability are shifted southeastwards and more zonally oriented as compared to those of the NAO. However, recent works characterize it as a well-defined sea level pressure (SLP) monopole south of Iceland and west of Ireland (e.g., Moore et al. 2013; Comas-Bru and McDermott 2014; Comas-Bru and Hernández 2018). These works have indicated that the EA also modulates the location of the North Atlantic action centers and can shape the surface responses to the NAO. For example, the EA played a key role in determining the climate anomalies during the outstanding negative NAO episodes associated with the extremely cold European events of December 2010 and winter 2006/ 07 (Moore et al. 2011; Moore and Renfrew 2012). Besides, Bastos et al. (2016) show that both patterns influence European land $\mathrm{CO}_{2}$ sink, underscoring the necessity of characterizing better their joint effects.

The variability of the North Atlantic eddy-driven jet stream can be largely described using a combination of NAO and EA. These indices reflect winter changes in the latitude and speed of the North Atlantic jet stream (Woollings et al. 2010; Woollings and Blackburn 2012). In turn, these parameters of the jet are strongly related to the location of the North Atlantic storm tracks (e.g., Pinto et al. 2007) and the occurrence of wavelike weather regimes (e.g., Woollings et al. 2018). The latitude and waviness of the North Atlantic jet also modulate the occurrence of midlatitude weather extremes in observational and model studies (Mahlstein et al. 2012; Röthlisberger et al. 2016). Indeed, future regional changes in European climate strongly depend on the responses of the jet stream to climate change, which are subject to large uncertainties (e.g., Zappa and Shepherd 2017; Peings et al. 2018). This limited understanding of the jet stream variability is partially hampered by the short observational record of wind measurements in the historical period, which are mostly constrained to the twentieth century (Garcia-Herrera et al. 2018, and references therein).

In recent decades, much work has been done to extend NAO indices back in time. The longest highresolution series are based on indirect proxy records (e.g., Cook et al. 1998; Appenzeller et al. 1998; Ortega et al. 2015; Sjolte et al. 2018, and references therein), which tend to show notable discrepancies in the preindustrial period (Schmutz et al. 2000; Schultz et al. 2015), while those relying on observations only reach the eighteenth century (e.g., Jones et al. 1997; Luterbacher et al. 2001). As a consequence, the variability of the NAO further back in time remains only partially answered (Hurrell et al. 2003). Less effort has been made to extend the EA backward beyond the instrumental record. Moore and Renfrew (2012) derived an EA index since 1870 based on historical SLP data, which have recently been updated and extended back to 1851 by Comas-Bru and Hernández (2018). However, the evolution of the EA before the mid-nineteenth century remains unknown, and the few existing studies considering the NAO, EA, and their interactions are limited to the twentieth century. The integrated assessment of these indices and their joint exploitation to infer the variability of the eddy-driven jet in the historical period is also missing.

In this paper we use the directional indices (DIs) built from wind direction observations over the English Channel (Mellado-Cano et al. 2018, 2019, manuscript submitted to Climate Dyn.) to extend back current records of NAO and EA, analyze their multiple combinations and exploit them to reconstruct the variability of the North Atlantic jet stream since the end of the seventeenth century. The derived winter series constitute powerful tools to characterize the Euro-Atlantic climate variability from high to low frequencies, since they are based on observations and cover the 1685-2014 period, extending current records beyond the industrial period.

\section{Data}

We employ the time series of the DIs (Mellado-Cano et al. 2018, 2019, manuscript submitted to Climate Dyn.), 
TABLE 1. Performance of the first (SVD1) and second (SVD2) singular vectors of the DIs with respect to traditional NAO and EA indices, as diagnosed by the Pearson correlation coefficient and RMSE for 1951-2001. Significant correlations at $p<0.01$ are highlighted in bold. All indices are standardized for the 1951-2001 period.

\begin{tabular}{|c|c|c|c|c|}
\hline Index & Definition & Period & $R: \mathrm{SVD} 1 / \mathrm{SVD} 2$ & RMSE: SVD1/SVD2 \\
\hline \multicolumn{5}{|c|}{ NAO } \\
\hline CPC NOAA & $\begin{array}{l}\text { First rotated } \mathrm{PC} \text { of standardized } \\
\text { geopotential height anomalies at } \\
500 \mathrm{hPa} \text { for }\left(20^{\circ}-90^{\circ} \mathrm{N}\right)\end{array}$ & 1950-2014 & $\mathbf{0 . 6 1} /-0.22$ & $0.88 / 1.54$ \\
\hline Hurrell (1995) & $\begin{array}{l}\text { First PC of SLP anomalies over the Atlantic } \\
\text { sector }\left(20^{\circ}-80^{\circ} \mathrm{N}, 90^{\circ} \mathrm{W}-40^{\circ} \mathrm{E}\right)\end{array}$ & 1901-2014 & $\mathbf{0 . 4 9} /-0.18$ & $1.00 / 1.52$ \\
\hline Jones et al. (1997) & $\begin{array}{l}\text { Normalized pressure difference between } \\
\text { Azores [Ponta Delgada }\left(37.7^{\circ} \mathrm{N}, 25.7^{\circ} \mathrm{W}\right) \text { ] } \\
\text { and Iceland [Akureyri }\left(65.7^{\circ} \mathrm{N}, 18.1^{\circ} \mathrm{W}\right) \\
\left.\text { and Stykkisholmur }\left(65.0^{\circ} \mathrm{N}, 22.8^{\circ} \mathrm{W}\right)\right]\end{array}$ & 1824-2014 & $\mathbf{0 . 7 4} /-0.17$ & $0.72 / 1.51$ \\
\hline $\begin{array}{l}\text { Luterbacher et al. } \\
\qquad(2002)\end{array}$ & $\begin{array}{l}\text { Standardized SLP difference between } \\
\text { Azores and Iceland, each region defined } \\
\text { as the mean of four grid points on a } \\
5^{\circ} \times 5^{\circ} \text { grid }\end{array}$ & $1685-2001$ & $\mathbf{0 . 7 7} /-0.24$ & $0.68 / 1.56$ \\
\hline CPC NOAA & $\begin{array}{l}\text { EA } \\
\text { Second rotated PC of standardized } \\
\text { geopotential height anomalies at } \\
500 \mathrm{hPa} \text { for }\left(20^{\circ}-90^{\circ} \mathrm{N}\right)\end{array}$ & 1950-2014 & $0.34 / 0.54$ & $1.14 / 0.95$ \\
\hline Second EOF SLP ERA-20C & $\begin{array}{l}\text { Second PC of the monthly standardized } \\
\text { area-weighted SLP anomaly over } \\
\left(10^{\circ}-80^{\circ} \mathrm{N}, 100^{\circ} \mathrm{W}-40^{\circ} \mathrm{E}\right)\end{array}$ & $1901-2010$ & $-0.37 / 0.71$ & $1.64 / 0.75$ \\
\hline $\begin{array}{l}\text { Comas-Bru and } \\
\text { Hernández (2018) }\end{array}$ & $\begin{array}{l}\text { Composite of EA series constructed from } \\
\text { two historical records (Bergen Florida } \\
\text { and Valentia) and five reanalyses }\end{array}$ & $1852-2014$ & $0.18 / \mathbf{0 . 7 0}$ & $1.27 / 0.77$ \\
\hline
\end{tabular}

which have monthly resolution and cover the 1685-2014 period, with only some missing months. They are derived from daily wind direction observations obtained over the English Channel, mostly kept in ships' logbooks (García-Herrera et al. 2018) and measure the persistence of the wind (in percentage of days in the month) in the four main cardinal directions: northerly, southerly, easterly, and westerly. The reader is referred to Mellado-Cano et al. (2019, manuscript submitted to Climate Dyn.) for further information on data sources and the construction of the DIs. These indices have been shown to provide additional information to that of the NAO (Vicente-Serrano et al. 2018; Mellado-Cano et al. 2019, manuscript submitted to Climate Dyn.), also capturing unusual periods in the recent (Barriopedro et al. 2014) and preindustrial (Mellado-Cano et al. 2018) eras. Therefore, they should be considered as optimal benchmarks to characterize the Euro-Atlantic climate variability of the last three centuries.

The DIs are herein employed to construct NAO and EA indicators for the 1685-2014 period, from which the North Atlantic jet stream speed and latitude can be inferred. We have focused on winter [DecemberFebruary (DJF)] means, when NAO and EA are more active dynamically and explain the largest variance of atmospheric circulation (Hurrell et al. 2003; Trigo et al.
2008; Comas-Bru and Hernández 2018). For comparative purposes, we have also used other NAO and EA indices, obtained from different data sources, fields, domains and methodologies. They include (Table 1): the principal component (PC) NAO index of Hurrell (1995) and the station-based indices of Jones et al. (1997) and Luterbacher et al. (2001), all derived from SLP data; the EA index of Comas-Bru and Hernández (2018), obtained from a multireanalysis PC-based approach; the EA index defined as the second PC from SLP data of the twentieth-century ECMWF ReAnalysis (ERA-20C; Poli et al. 2016); the NAO and EA indices provided by the Climate Prediction Center (CPC) of the NOAA (https://www.cpc.ncep.noaa.gov/ data/teledoc/telecontents.shtml) based on a rotated PC analysis of geopotential height at $500 \mathrm{hPa}(\mathrm{Z} 500)$ from the NCEP-NCAR reanalysis (Kalnay et al. 1996).

To explore the surface signatures of NAO and EA indices we used monthly near-surface temperature from the CRU TS3 database of the Climatic Research Unit (Harris et al. 2014) and total monthly precipitation from the Global Precipitation Climatology Centre (GPCC; Schamm et al. 2014). They are provided on a grid of $1^{\circ} \times 1^{\circ}$ longitude-latitude over land for 1901-2014. In addition, monthly Z500 and SLP data were obtained from the ERA$20 \mathrm{C}$ reanalysis with $2.5^{\circ} \times 2.5^{\circ}$ spatial resolution. 
Finally, daily parameters of the North Atlantic jet stream were computed from zonal wind data of the ERA-20C reanalysis for the 1901-2010 period, based on the methodology of Woollings et al. (2010). The lowlevel $(925-700 \mathrm{hPa})$ mean zonal wind was first smoothed with a low-pass (10-day) filter and averaged from $0^{\circ}$ to $60^{\circ} \mathrm{W}$. For each day, the jet location corresponds to the latitude between $15^{\circ}$ and $75^{\circ} \mathrm{N}$ where this zonal-mean zonal wind maximizes, and the jet speed is defined as the zonal wind at that latitude. These daily series were averaged to obtain winter means.

\section{Results}

\section{a. NAO and EA indices}

A singular value decomposition (SVD) analysis (Wilks 2011) was applied to the 1685-2014 winter series of the four DIs, retaining the two first singular vectors, which explain $44 \%$ and $35 \%$ of the total variance, respectively. Similar results were obtained by applying the same analysis to the DIs series of each calendar month separately (December: 45\%, 34\%; January: 43\%, 36\%; February $44 \%, 35 \%)$. Figure 1 shows the regression patterns of SLP (shading) and Z500 (contours) onto these singular vectors. Despite their regional character, the singular vectors are associated with substantial atmospheric circulation anomalies over large areas of the Euro-Atlantic sector, including changes in the location/ intensity of the North Atlantic action centers. The first (second) singular vector reflects a meridional (almost zonal) dipole that resembles the NAO (EA) pattern. Overall, their signatures in near-surface climate fields (temperature and precipitation) also agree well with those reported elsewhere for traditional NAO (e.g., Trigo et al. 2002) and EA (Comas-Bru and McDermott 2014) indices (not shown). Divergences with instrumental indices could be due to differences in their underlying dynamical information (e.g., ageostrophic component of the wind missed by indices based on pressure gradients) and the target region (an eastern location of the English Channel with respect to the centers of variability of the NAO). However, in general, they are not substantially larger than the discrepancies obtained between different instrumental indices (not shown).

To further explore this question, Table 1 shows the Pearson correlation coefficients and the rootmean-square errors (RMSEs) between these singular vectors and different $\mathrm{NAO}$ and $\mathrm{EA}$ indices for the 1951-2001 common period of all indices. All NAO (EA) indices display significant correlations at $p<$ 0.01 with the first (second) singular vector of the DIs

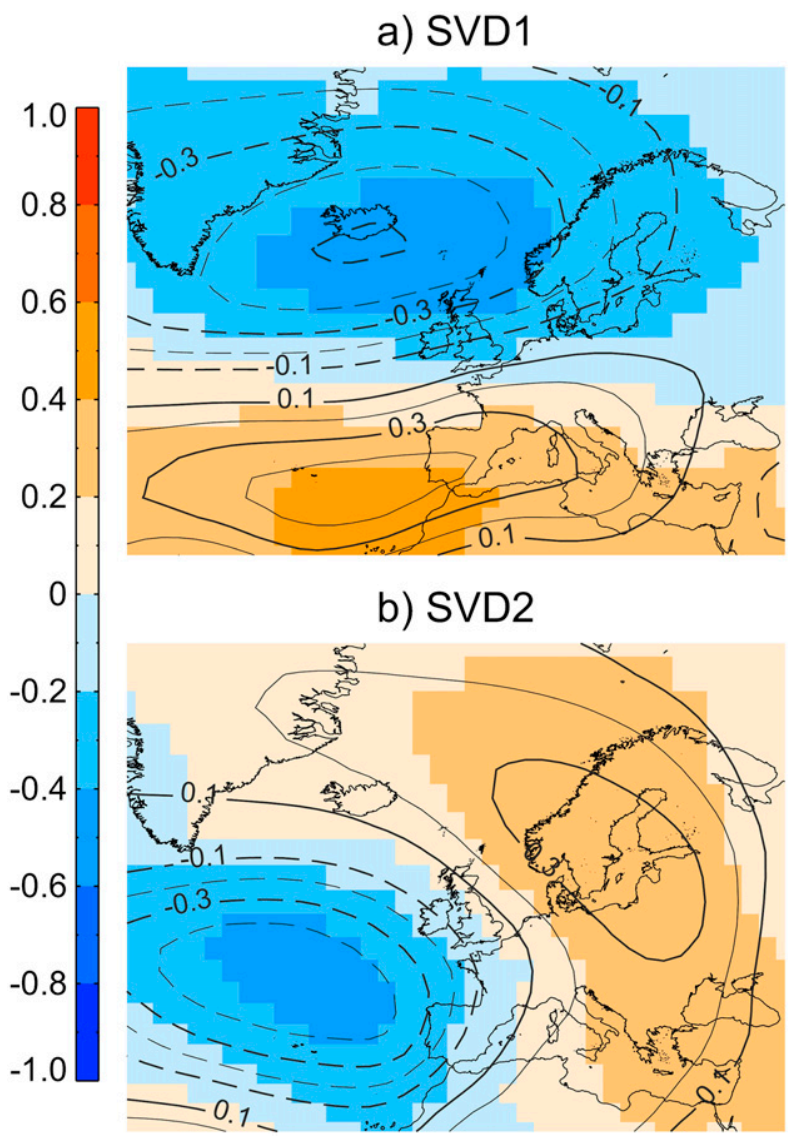

FIG. 1. Regression coefficients of the winter SLP (shading) and Z500 (contours) anomaly fields onto (a) the first and (b) the second singular vector of the DIs for the period 1901-2010.

and insignificant or very weak correlations with the second (first) one. The same result is obtained if we analyze the full period of each reference index (not shown). The highest correlation with the first singular vector corresponds to the NAO index of Jones et al. (1997), and remains constant with time (e.g., $r=0.67$, $p<0.01$ for their common overlapping period 1824 2014). Similar correlation coefficients are obtained between the second singular vector and the EA index of Comas-Bru and Hernández (2018) for the 19502014 period. However, in this case, the relationship tends to weaken back in time $(r=0.48, p<0.01$ for their common overlapping period 1852-2014), arguably because of methodological issues in the definition of that EA index, which involves a multireanalysis ensemble mean. Still, the correlations observed with the second singular value are of similar magnitude to those obtained between other EA indices (e.g., $r=-0.58$ for the EA indices of CPC and Valentia SLP series), stressing the differences between its multiple definitions. 
On the other hand, the RMSE of the first and second singular vectors with respect to the aforementioned NAO and EA indices, respectively, is $\sim 0.7$, slightly higher than those obtained between some canonical indices of the NAO $[\sim 0.6$, e.g., for the NAO indices of Jones et al. (1997) and CPC], and within the range of the values retrieved among traditional EA indices [e.g., $\sim 0.8$ for the EA indices of Comas-Bru and Hernández (2018) and CPC]. As compared to the reference values derived from the intercomparison of instrumental indices for the 1951-2001 period, the skill of the second singular vector is slightly better than that of the first one. This is partially explained by the large diversity (and hence performances) of EA indices, as compared to those of NAO, and the fact that the first singular vector performs worse for PC-based than station-based NAO indices. Indeed, if the comparison is limited to stationbased NAO definitions, we obtain similar skills for the two singular vectors. Therefore, the first and second singular vectors of the DIs can be considered good indicators of the NAO and EA, respectively, and hereafter they will be referred to as $\mathrm{NAO}_{\mathrm{DI}}$ and $\mathrm{EA}_{\mathrm{DI}}$.

Figures $2 \mathrm{a}$ and $2 \mathrm{~b}$ show the standardized (1685-2014) winter series of $\mathrm{NAO}_{\mathrm{DI}}$ and $\mathrm{EA}_{\mathrm{DI}}$ for the last 330 years (black lines), with red (blue) colors indicating 7-yr running mean values above (below) zero. $\mathrm{NAO}_{\mathrm{DI}}$ captures the most outstanding anomalous periods reported in previous studies, including the dominant positive phases during 1900-30 and 1970-2000 as well as the persistent negative phase between 1820 and 1845 and the 1960s (Jones et al. 1997; Visbeck et al. 2001; Slonosky and Yiou 2001; Luterbacher et al. 2001; Trouet et al. 2009; Cornes et al. 2013). The NAO ${ }_{\text {DI }}$ series also displays extreme negative values for the well-known cold winters of 1916/17 $\left(\mathrm{NAO}_{\mathrm{DI}}=-1.97 \mathrm{SD}\right)$ and 1962/63 $\left(\mathrm{NAO}_{\mathrm{DI}}=-2.30 \mathrm{SD}\right)$ (Cornes et al. 2013; Greatbatch et al. 2015). The same level of agreement applies to the $\mathrm{EA}_{\mathrm{DI}}$ index, which captures the predominance of positive phases at the end of the nineteenth century and the subsequent reversal at the beginning of the twentieth century (Comas-Bru and Hernández 2018). It also reflects extreme episodes on different time scales, such as the recurrent negative values in the 1950s reported by the CPC EA index or the extreme 2004/05 winter $\left(\mathrm{EA}_{\mathrm{DI}}=-1.40 \mathrm{SD}\right)$. Therefore, our indices are excellent indicators of outstanding periods associated with prominent anomalies of the two leading patterns of atmospheric variability over the Euro-Atlantic sector, as reported by the instrumental record. They provide the longest observational-based series of NAO and EA, extending current records by more than 150 years in the case of EA. Superimposed on the aforementioned signatures, our series also show large variability on very
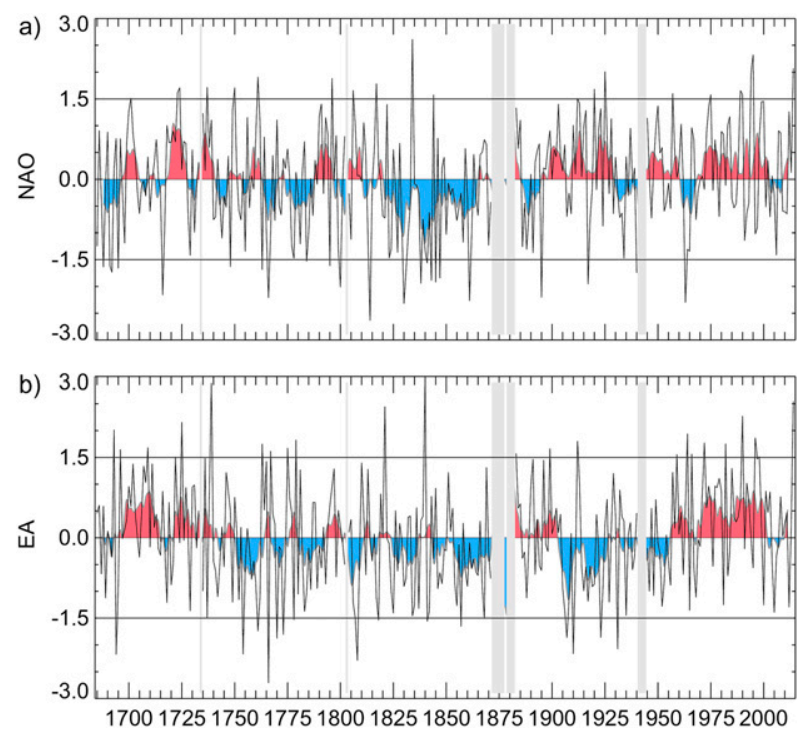

FIG. 2. Winter standardized series of: (a) $\mathrm{NAO}_{\mathrm{DI}}$ and (b) $\mathrm{EA}_{\mathrm{DI}}$ for 1685-2014 (in SD, black line) and a 7-yr running mean (gray line), with red (blue) shading indicating periods above (below) the 1695-2014 mean. Vertical gray shading identifies periods of missing data.

low frequencies (multidecadal and longer). The $\mathrm{EA}_{\mathrm{DI}}$ negative phase dominated during the 1750-1950 period (blue in Fig. 2b), while the positive phase prevailed before 1750 and after 1950 . The $\mathrm{NAO}_{\mathrm{DI}}$ shows a more alternating behavior until 1800 , with a certain prevalence of the negative phase along the nineteenth century.

\section{b. The combined role of $N A O$ and $E A$ in Euro-Atlantic climate}

To determine the joint effects of the $\mathrm{NAO}_{\mathrm{DI}}$ and $\mathrm{EA}_{\mathrm{DI}}$ (Fig. 1) on the Euro-Atlantic climate we have partitioned the $2 \mathrm{D} \mathrm{NAO}_{\mathrm{DI}} / \mathrm{EA}_{\mathrm{DI}}$ phase space, thus defining four combinations of the $\mathrm{NAO}_{\mathrm{DI}}$ and $\mathrm{EA}_{\mathrm{DI}}$ indices (Fig. 3): $\mathrm{NAO}_{\mathrm{DI}}+/ \mathrm{EA}_{\mathrm{DI}}+, \mathrm{NAO}_{\mathrm{DI}}+/ \mathrm{EA}_{\mathrm{DI}}{ }^{-}$, $\mathrm{NAO}_{\mathrm{DI}^{-}}-/ \mathrm{EA}_{\mathrm{DI}}+$, and $\mathrm{NAO}_{\mathrm{DI}}-/ \mathrm{EA}_{\mathrm{DI}}-$. The analysis is restricted to the period of available data in the reanalysis and observational datasets (1901-2014). These groups only contain winters with absolute values of $\mathrm{NAO}_{\mathrm{DI}}$ and $\mathrm{EA}_{\mathrm{DI}}$ larger than $0.5 \mathrm{SD}$. This criterion provides a balanced and sufficient number of cases (see the left bottom corner of each panel in Fig. 3), excluding winters with weak signals of either $\mathrm{NAO}_{\mathrm{DI}}$ or $\mathrm{EA}_{\mathrm{DI}}$. The resulting composites for each combination are weaker but qualitatively similar if the above threshold is omitted, therefore cataloguing all winters in one of the four groups (not shown). Our approach is similar to that adopted by Comas-Bru and McDermott (2014), except that they only considered two groups formed by winters 

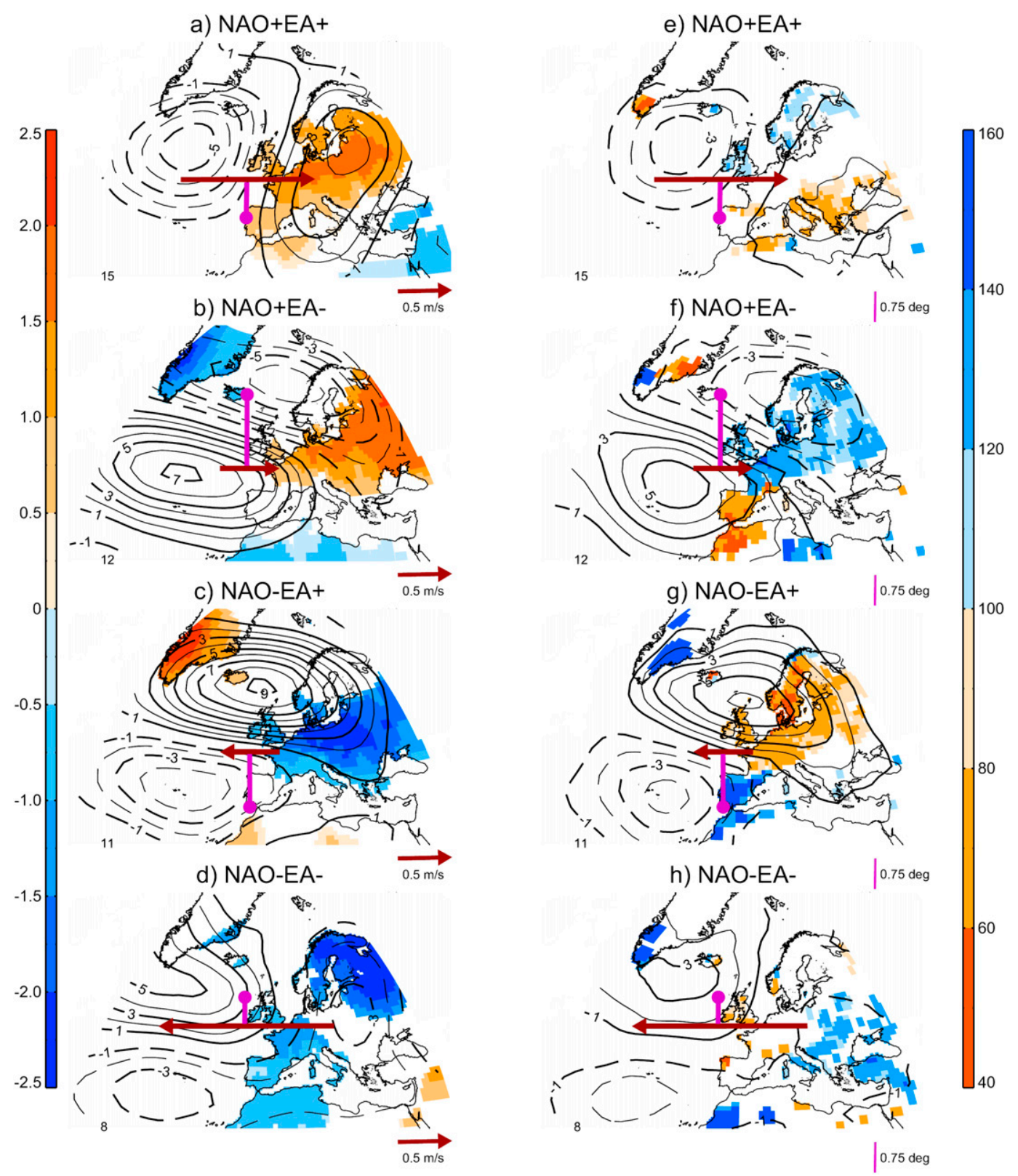

FIG. 3. Winter composites of: (a)-(d) near-surface temperature (shading, in ${ }^{\circ} \mathrm{C}$ ) and geopotential height at $500 \mathrm{hPa}$ (contours, in dam) anomalies; (e)-(h) precipitation (shading, in percentage of normals) and SLP (contours, $\mathrm{hPa}$ ) anomalies for different combinations of $\mathrm{NAO}_{\mathrm{DI}}$ and $\mathrm{EA}_{\mathrm{DI}}$ indices with absolute values larger than 0.5 SDs: (a) $\mathrm{NAO}_{\mathrm{DI}}+/ \mathrm{EA}_{\mathrm{DI}}+$, (b) $\mathrm{NAO}_{\mathrm{DI}}+/ \mathrm{EA}_{\mathrm{DI}}^{-}$, (c) $\mathrm{NAO}_{\mathrm{DI}}-/ \mathrm{EA}_{\mathrm{DI}}+$, and (d) $\mathrm{NAO}_{\mathrm{DI}}-/ \mathrm{EA}_{\mathrm{DI}}-$. Anomalies are computed with respect to 1901-2010. Numbers in the left bottom corner of each panel represent the number of cases employed in each composite. Only temperature and precipitation anomalies that are significantly different $(p<0.05)$ from the climatology are shown, after a 5000-trial bootstrap test. Horizontal red arrows and vertical purple lines summarize the composited winter anomalies of the jet speed and latitude respectively, with the length being proportional to the anomaly. Eastward (westward) red arrows indicate a strengthening (weakening) of the jet. Purple lines pointing upward (downward) indicate a poleward (equatorward) shift of the jet.

with equal and opposite phases of NAO and EA, thus disregarding asymmetric responses between positive and negative phases, as those reported for the NAO (e.g., Cornes et al. 2013).
To lend further support to our results, this analysis was repeated for the same period of the NAO and EA indices of Jones et al. (1997) and Comas-Bru and Hernández (2018), respectively (Fig. 4). Note that differences 


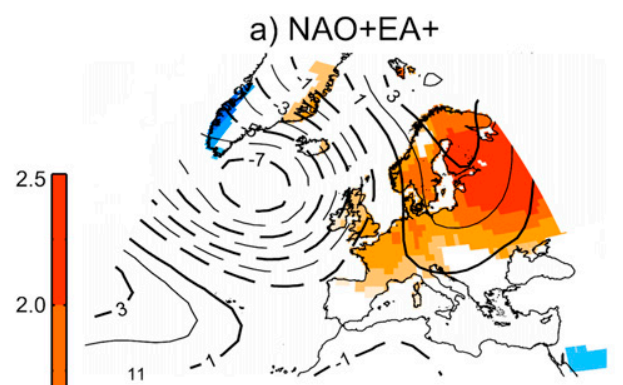

b) $\mathrm{NAO}+\mathrm{EA}-$

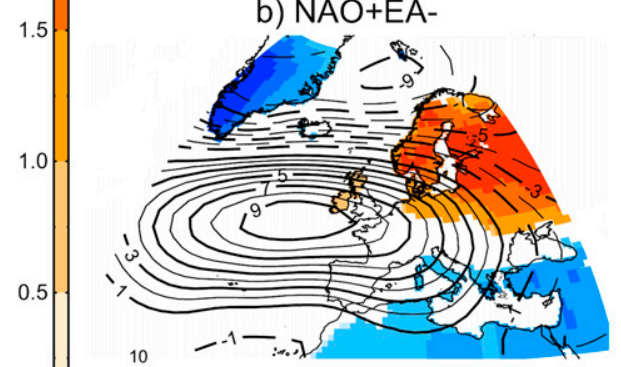

c) NAO-EA+

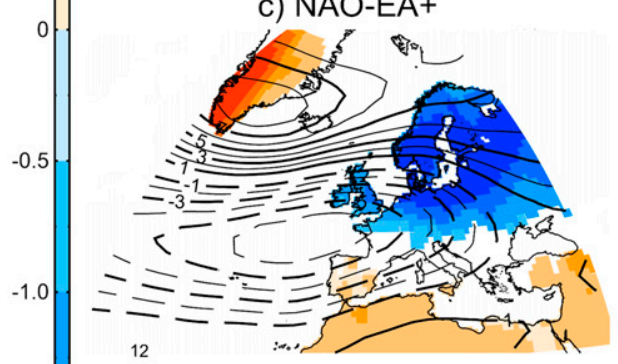

d) NAO-EA-

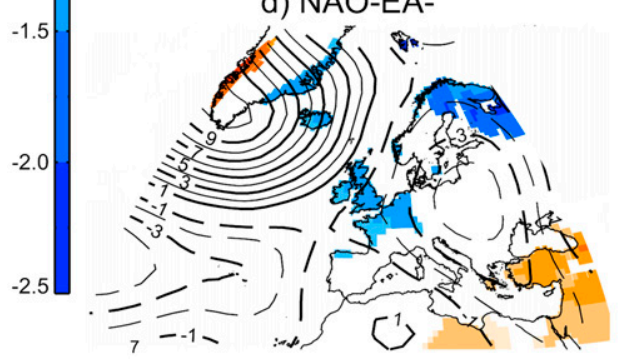

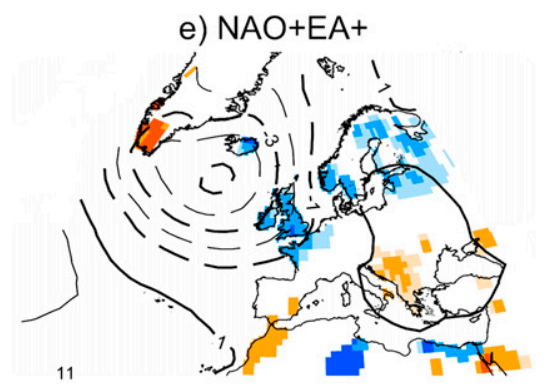

f) $\mathrm{NAO}+\mathrm{EA}-$

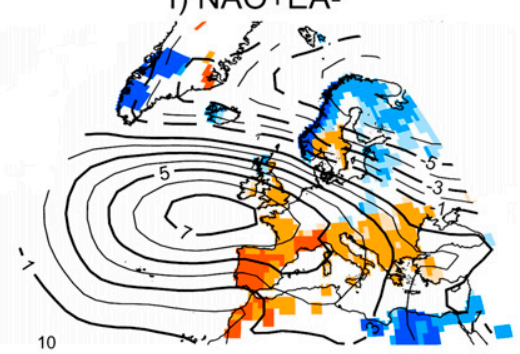

g) NAO-EA+

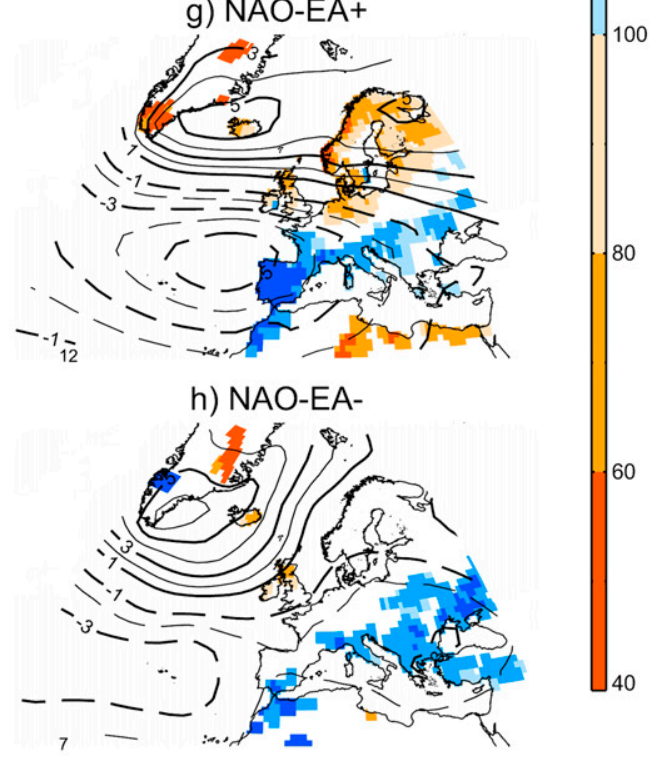

FIG. 4. As in Fig. 2, but for the NAO of Jones et al. (1997) and the EA of Comas-Bru and Hernández (2018).

between Figs. 3 and 4 can be due to discrepancies between indices and/or the resulting number of winters employed in the composites. Still, these differences mainly concern to the areal extent of statistical significance rather than the sign of the anomalies, and are not dramatically larger than those observed between the indices of Fig. 4 and other instrumental series of the NAO and EA (not shown).

Figure 3 shows the composites of winter anomalies in atmospheric circulation (Z500 and SLP, contours) and nearsurface (2-m temperature and precipitation, shading) fields for each combination of indices. All $\mathrm{NAO}_{\mathrm{DI}} / \mathrm{EA}_{\mathrm{DI}}$ combinations display a pressure dipole, but exhibit differences in its location, intensity, and spatial extension. When the $\mathrm{NAO}_{\mathrm{DI}}$ and $\mathrm{EA}_{\mathrm{DI}}$ are in the same phase (Figs. 3a,e,d,h), the southern center of action shifts eastward toward Europe, while the northern center retreats toward the Atlantic (see also Figs. 4a,e,d,h). As a consequence, the North Atlantic jet stream displays changes in the typical southwest-northeast tilt. This can occur at expense of the westerlies (i.e., a wavier pattern; Figs. 3d,h, $\mathrm{NAO}_{\mathrm{DI}^{-}}-\mathrm{EA}_{\mathrm{DI}^{-}}{ }^{-}$) or be accompanied by a stronger jet (i.e., an enhanced southwest-northeast tilt of the jet; Figs. 3a,e, $\mathrm{NAO}_{\mathrm{DI}}+/ \mathrm{EA}_{\mathrm{DI}}+$ ). This is supported by the corresponding composites of jet speed anomalies, which show a reinforced jet for $\mathrm{NAO}_{\mathrm{DI}}+/ \mathrm{EA}_{\mathrm{DI}}+$ and the opposite for $\mathrm{NAO}_{\mathrm{DI}}-/ \mathrm{EA}_{\mathrm{DI}}-$ (horizontal red arrows in 
Figs. 3a,d), with relatively weaker anomalies in the jet latitude. On the other hand, when the $\mathrm{NAO}_{\mathrm{DI}}$ and $\mathrm{EA}_{\mathrm{DI}}$ have opposite phases (Figs. 3b,f,c,g) the northern and southern anomaly centers shift toward Europe and the Atlantic, respectively, as compared to winters of equal phases, resulting in a meridionally oriented dipole (see also Figs. 4b,f,c,g). In this case the anomalies in the jet latitude are larger than those obtained when both indices are in the same phase, with a poleward shift of the jet for $\mathrm{NAO}_{\mathrm{DI}}+/ \mathrm{EA}_{\mathrm{DI}}-$ (vertical red arrows in Figs. $3 b, f)$ and equatorward migrations for $\mathrm{NAO}_{\mathrm{DI}}-/ \mathrm{EA}_{\mathrm{DI}}+$ (Figs. 3d,h).

Overall, our results indicate that $\mathrm{NAO}_{\mathrm{DI}}$ and $\mathrm{EA}_{\mathrm{DI}}$ induce anomalies of the same sign in the jet speed but have opposite effects in the jet latitude. The role of $\mathrm{EA}_{\mathrm{DI}}$ seems to occur through the tilt of the jet, with the positive phase favoring a stronger and reinforced southwest-northeast tilt (i.e., southward displacements in the North Atlantic and the opposite in the exit region of Europe). Using daily data, Woollings et al. (2010) identified three nodal locations for the North Atlantic jet stream in northern, central, and southern latitudes. According to our results, winters with a central jet position tend to occur when $\mathrm{NAO}_{\mathrm{DI}}$ and $\mathrm{EA}_{\mathrm{DI}}$ display the same sign, while meridional displacements dominate in winters of opposite phases, being poleward (equatorward) for $\mathrm{NAO}_{\mathrm{DI}}+/ \mathrm{EA}_{\mathrm{DI}}-\left(\mathrm{NAO}_{\mathrm{DI}}-/ \mathrm{EA}_{\mathrm{DI}}+\right)$.

We next turn attention to the composites of surface climate anomalies for the different partitions of the $\mathrm{NAO}_{\mathrm{DI}} / \mathrm{EA}_{\mathrm{DI}}$ phase space. The sign of the temperature anomalies is largely determined by the $\mathrm{NAO}_{\mathrm{DI}}$, with warmer winters in most of continental Europe for all combinations with positive $\mathrm{NAO}_{\mathrm{DI}}$ phases (Figs. 3a,b) and relatively colder conditions for winters of negative $\mathrm{NAO}_{\text {DI }}$ (Figs. 3c,d). However, the EA ${ }_{\text {DI }}$ shapes this overall picture by modulating the regions with significant temperature anomalies, which tend to shift from central to northeastern Europe when the $\mathrm{EA}_{\mathrm{DI}}$ changes from positive (Figs. 3a,c) to negative (Figs. 3b,d) phases. Analogously, Greenland exhibits larger anomalies when the $\mathrm{EA}_{\mathrm{DI}}$ phase is opposite to that of $\mathrm{NAO}_{\mathrm{DI}}$ (Figs. 3b,c and $4 \mathrm{~b}, \mathrm{c})$. In addition, there are areas where the additional role of one of the indices is able to alter the expected temperature response to the other. For example, under $\mathrm{NAO}_{\mathrm{DI}}{ }^{+}$, southwestern Europe tends to exhibit warming if $\mathrm{EA}_{\mathrm{DI}}$ is in a positive phase (Fig. 3a), but no significant signals for $\mathrm{EA}_{\mathrm{DI}}-$ (Fig. $3 b$ ). Therefore, the reported signatures of EA in Iberian winter temperature (Sáenz et al. 2001; Toreti et al. 2010; Hernández et al. 2015; Sánchez-López et al. 2016) change under the additional effects of NAO. Similarly, Greenland warming, typically associated with pervasive blocking conditions during negative NAO phases (Davini et al. 2012; Hanna et al. 2016), is more pronounced for $\mathrm{EA}_{\mathrm{DI}}+$ (Fig. 3c) but substantially damped and even reversed under $\mathrm{EA}_{\mathrm{DI}}-$ (Fig. 3d).

On the other hand, precipitation anomalies (Fig. 3, right panels) are overall more sensitive to the concomitant state of $\mathrm{NAO}_{\mathrm{DI}}$ and $\mathrm{EA}_{\mathrm{DI}}$ than temperature, although the areas displaying significant responses are comparatively reduced (see also Fig. 4, right panels). Widespread precipitation responses occur in winters with opposite phases of $\mathrm{NAO}_{\mathrm{DI}}$ and $\mathrm{EA}_{\mathrm{DI}}$ (Figs. 3f,g), since these combinations reflect the largest anomalies in the jet latitude, which largely controls the trajectories of the moisture transport into Europe. As such, when acting together, the $\mathrm{EA}_{\mathrm{DI}}$ substantially alters the precipitation responses prompted by the $\mathrm{NAO}_{\mathrm{DI}}$. For example, $\mathrm{NAO}_{\mathrm{DI}}-/ \mathrm{EA}_{\mathrm{DI}}+$ (Fig. $3 \mathrm{~g}$ ) is the only combination leading to significant precipitation increases in the Iberian Peninsula. Surprisingly, this region is among the areas with the strongest responses to the NAO (e.g., Trigo et al. 2002), meaning that the $E A_{D I}$ can even overwhelm the NAO effects, even in canonical regions of important NAO fingerprints. These unexpected results are in agreement with the opposite effects of $\mathrm{NAO}_{\mathrm{DI}}$ and $\mathrm{EA}_{\mathrm{DI}}$ on the jet latitude. During $\mathrm{NAO}_{\mathrm{DI}}-/ \mathrm{EA}_{\mathrm{DI}}+$ both patterns contribute to a southward shift of the jet and enhanced storminess in southern Europe (Fig. 3g). Precipitation increases are particularly pronounced in southwestern Europe and weaken eastward, the latter being in agreement with the extension of high-pressure anomalies toward central and eastern Europe. In contrast, the $\mathrm{NAO}_{\mathrm{DI}}-/ \mathrm{EA}_{\mathrm{DI}}{ }^{-}$ combination is less efficient in displacing the jet because of their competing effects in the jet latitude (Figs. 3d,h). In this case, positive pressure anomalies are confined to eastern Atlantic midlatitudes, impeding the entrance of storm tracks to the westernmost sector of southern Europe (see also Figs. 3d,h). The resulting weaker and wavier jet allows storm tracks to be diverted northward or southward of the high-pressure center (not shown). This configuration leaves a corridor of low pressure through northern Africa toward eastern Mediterranean that has also been associated with anomalies in the African jet (Gaetani et al. 2011). These results indicate that the Mediterranean precipitation responses in NAO- composites arise from mixing winters with larger precipitation signals in either western or eastern Mediterranean, which are influenced by the additional role of EA. A similar behavior is found for positive $\mathrm{NAO}_{\mathrm{DI}}$ phases (Figs. 3e,f). As such, under active EA phases, the canonical precipitation signature attributed to NAO in southwestern Europe only manifests when EA is in the opposite phase. If EA is in phase with the NAO, the signal shifts eastward, leading to weaker precipitation responses in that region (see also Fig. 4). This west-east shift of the canonical NAO signal 
TABLE 2. Stepwise regression model of the (top) jet speed and (bottom) latitude standardized anomalies onto the NAO $\mathrm{DI}_{\mathrm{D}}$ and $\mathrm{EA}_{\mathrm{DI}}$ indices for the 1945-2010 calibration period (first two columns) and the 1901-44 validation period (last two columns). For the calibration period, the first two rows indicate the regression coefficients for each index with their $p$ values in parentheses (based on a $t$ test with null hypothesis of zero coefficient). The last row shows the multiple correlation coefficient of the SRM (i.e., explained variance by the selected predictors) with the $p$ value of the goodness-of-fit $F$ statistic in parentheses. For the validation period, the following diagnostics of the reconstructed series are shown: Pearson correlation coefficient ( $R$, with the $p$ value in parentheses), RMSE (in SD) and RE (dimensionless)/CE (dimensionless).

\begin{tabular}{llccc}
\hline \hline Predictand & Predictor & Calibration & Diagnostic & Validation \\
\hline \multirow{2}{*}{ Jet speed } & NAO $_{\text {DI }}$ & $0.68(<0.01)$ & $R$ & 0.79 \\
& EA $_{\text {DI }}$ & $0.22(<0.02)$ & RMSE & 0.59 \\
All & $0.66(<0.01)$ & RE/CE & $R$ & $0.65 / 0.61$ \\
Jet latitude & NAO & $0.30(<0.01)$ & RMSE & 0.38 \\
& EA & $-0.37(<0.01)$ & RE/CE & 0.89 \\
& All & $0.43(<0.01)$ & $0.12 / 0.11$ \\
\hline
\end{tabular}

induced by the EA may explain the reported anticorrelation in drought severity between western (Iberia) and eastern (Turkey) Mediterranean for the twentieth century (Sousa et al. 2011)

\section{c. NAO, EA, and jet stream since 1685}

In the previous section we have reported how different combinations of $\mathrm{NAO}_{\mathrm{DI}}$ and $\mathrm{EA}_{\mathrm{DI}}$ have profound implications in the Euro-Atlantic climate variability through their effects in the latitude and speed of the eddy-driven jet. Herein, we explore the whole 1685 2014 record to address the relative frequencies of $\mathrm{NAO}_{\mathrm{DI}} / \mathrm{EA}_{\mathrm{DI}}$ combinations and their relevance to explain anomalous periods of the last three centuries. To further exploit the complementary information of these indices on the jet stream, we performed a stepwise regression model (SRM; Wilks 2011; Bruce and Bruce 2017) using either the latitude or speed of the jet as the dependent variable and the $\mathrm{NAO}_{\mathrm{DI}}$ and $\mathrm{EA}_{\mathrm{DI}}$ as the predictors. SRM finds the optimal combination of predictors by proceeding forwards and backward in the selection of predictors (i.e., adding and removing explanatory variables), and retaining only those that increase significantly the explained variance of the predictand. The SRM is calibrated over the 1945-2010 period, which samples enough the $\mathrm{NAO}_{\mathrm{DI}} / \mathrm{EA}_{\mathrm{DI}}$ phase space (similar results are obtained for the full 1901-2010 period). The regression coefficients of the selected predictors are then employed to reconstruct the latitude and speed of the jet stream for the 1685-2014 period, using the correlation coefficient, RMSE, reduction error (RE; e.g., Luterbacher et al. 2004), and coefficient of efficiency (CE; Briffa et al. 1988; Cook et al. 1999) as diagnostics over the 1901-44 validation period.

The SRM is able to explain a significant amount of the jet variance, being more skillful for the jet speed ( $r=$ $0.66)$ than for the jet latitude $(r=0.43)$ in the validation period (Table 2). Similar results are obtained for the other diagnostics, with positive RE and CE (i.e., better predictions than climatology). The performance of our SRM is also similar to that obtained from instrumental NAO and EA indices (not shown). For both jet parameters, the $\mathrm{NAO}_{\mathrm{DI}}$ and $\mathrm{EA}_{\mathrm{DI}}$ enter in the SRM, confirming their independent influences on the jet. As inferred from the regression coefficients of the SRM, $\mathrm{NAO}_{\mathrm{DI}}$, and $\mathrm{EA}_{\mathrm{DI}}$ have opposite (equally signed) effects on the jet latitude (speed), but with different loadings.

Figure 5a shows the frequency of the dominant $\mathrm{NAO}_{\mathrm{DI}} / \mathrm{EA}_{\mathrm{DI}}$ combination for each 7-yr interval of the 1685-2014 period, with the color identifying the specific pair: $\mathrm{NAO}_{\mathrm{DI}}+/ \mathrm{EA}_{\mathrm{DI}}+, \mathrm{NAO}_{\mathrm{DI}}+/ \mathrm{EA}_{\mathrm{DI}}-, \mathrm{NAO}_{\mathrm{DI}}-/$ $\mathrm{EA}_{\mathrm{DI}}{ }^{+}$, or $\mathrm{NAO}_{\mathrm{DI}^{-}}-/ \mathrm{EA}_{\mathrm{DI}}{ }^{-}$. Herein, all winters are catalogued in one of these four groups based on the sign of the indices. Moreover, Fig. 5b displays the 7-yr mean standardized anomalies of the jet latitude reconstructed from $\mathrm{NAO}_{\mathrm{DI}}$ and $\mathrm{EA}_{\mathrm{DI}}$, with orange (blue) colors indicating strengthening (weakening) of the jet for the same 7-yr mean periods. When the whole period is considered, there is a balanced frequency of $\mathrm{NAO}_{\mathrm{DI}} /$ $\mathrm{EA}_{\mathrm{DI}}$ combinations, with $\mathrm{NAO}_{\mathrm{DI}}-/ \mathrm{EA}_{\mathrm{DI}}+$ displaying slightly lower frequencies $(22.4 \%)$ than the rest. For the whole period, and independently of the combination considered, the $\mathrm{EA}_{\mathrm{DI}}$ is the dominant pattern (i.e., it displays absolute values larger than $\mathrm{NAO}_{\mathrm{DI}}$ ) in nearly $50 \%$ of the winters, indicating that the last three centuries cannot be properly described by the state of the $\mathrm{NAO}_{\mathrm{DI}}$ alone. Accordingly, the jet displayed substantial variability from interannual to centennial time scales, both in terms of intensity and latitudinal location. In spite of this, there are no hints of long-term trends or exceptional values for the last decades in the context of the last 330 years.

In addition, there are some periods that stand out from the dominance of a given $\mathrm{NAO}_{\mathrm{DI}} / \mathrm{EA}_{\mathrm{DI}}$ combination. For example, 1720-40 was characterized by recurrent positive phases of $\mathrm{NAO}_{\mathrm{DI}}$ and $\mathrm{EA}_{\mathrm{DI}}$ (Fig. 5a) as well as large anomalies in the jet (i.e., a stronger and 
a)
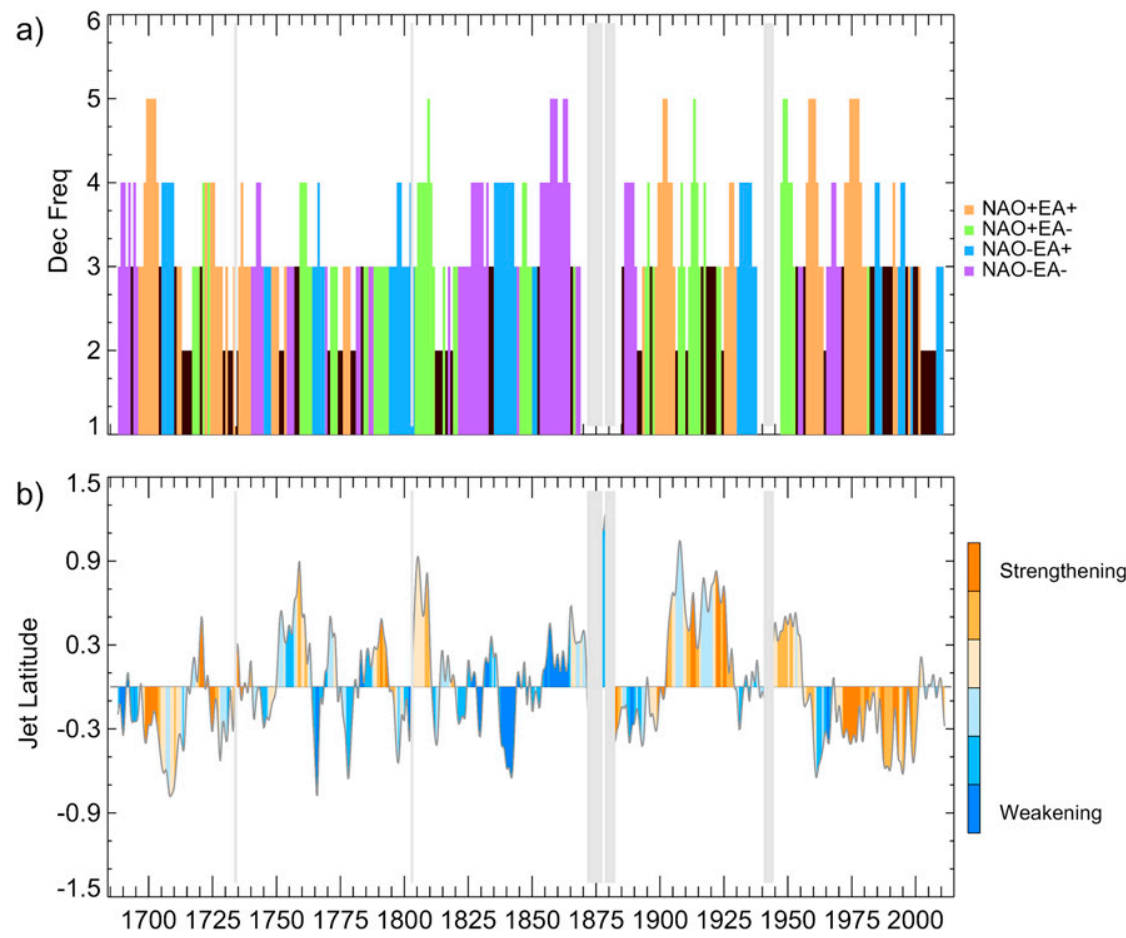

FIG. 5. (a) Frequency and type of the dominant winter $\mathrm{NAO}_{\mathrm{DI}} / \mathrm{EA}_{\mathrm{DI}}$ combination for each 7 yr interval of the 1685-2014 period, with the black color indicating intervals without a dominant combination. Vertical gray shading identifies periods of missing data; (b) reconstructed jet latitude anomaly (in SD with respect to 1685-2014) with a 7-yr running mean (gray line). The corresponding 7-yr running mean of the jet speed anomalies are shown in color, with orange (blue) colors shading denoting a strengthening (weakening) of the jet.

equatorward shifted jet, Fig. 5b), involving warm (cold) winters in north-central Europe (Greenland and eastern Mediterranean basin), as well as relatively dry (wet) conditions over Mediterranean (northern European) regions. This result provides a dynamical evidence of the reported shift toward increased precipitation in northern Europe (Jacobeit et al. 2003; Pauling et al. 2006) as well as the drought conditions in the south (DomínguezCastro et al. 2008) that followed the Late Maunder Minimum (LMM, 1700-15). Our time series also allow explaining individual extreme years. For example, the winter of 1783/84 that followed Laki's eruption was extremely cold around the circum-North Atlantic. D'Arrigo et al. (2011) suggested that the unusual conditions were caused by a negative NAO phase and a warm El Niño-Southern Oscillation event. Our results confirm the former $\left(\mathrm{NAO}_{\mathrm{DI}}=-1.54 \mathrm{SD}\right)$ event but also uncover a key role of the $\mathrm{EA}_{\mathrm{DI}}$, which was also in its negative phase $(-1.04 \mathrm{SD})$, both contributing to an extreme weakening of the jet.

Now, we turn attention to periods of contrasting phases between the $\mathrm{NAO}_{\mathrm{DI}}$ and $\mathrm{EA}_{\mathrm{DI}}$, which are those displaying the largest displacements of the jet stream. There were recurrent periods of $\mathrm{NAO}_{\mathrm{DI}}-/ \mathrm{EA}_{\mathrm{DI}}{ }^{+}$ through 1685-2014 (Fig. 2) characterized by southward excursions of the jet stream (Fig. 5b), including some decades of the LMM (Mellado-Cano et al. 2018). Although the period $1825-75$ was mostly dominated by negatives phases of $\mathrm{NAO}_{\mathrm{DI}}$ and $\mathrm{EA}_{\mathrm{DI}}$, the $\mathrm{EA}_{\mathrm{DI}}$ was in a positive phase during the 1840s (blue shading in Fig. 5b). Interestingly, Cornes et al. (2013) and Luterbacher et al. (2001) reported negative phases of the NAO during the 1830 s, but their indices disagree on the 1840s. Our results indicate that a shift in the phase of the $E A_{D I}$ prompted circulation changes (similar to those observed from Fig. 3d to Fig. 3c), which are not captured in the same way by the different NAO indices. On the other hand, Santos et al. (2013) described two recent and exceptional winters in the North Atlantic sector (2009/10 and 2011/12) with a contrasting behavior in the jet stream. In addition to the extreme negative (positive) NAO phase reported therein, our series evidence a measurable influence of $\mathrm{EA}_{\mathrm{DI}}+\left(\mathrm{EA}_{\mathrm{DI}}{ }^{-}\right)$in the southwardly (northwardly) shifted jet of 2009/10 (2011/12).

The combination $\mathrm{NAO}_{\mathrm{DI}}+/ \mathrm{EA}_{\mathrm{DI}}-$ dominated several intervals of the 1685-2014 period, most notably the beginning of the twentieth century (Fig. 5a), which was characterized by poleward excursions of the jet stream 
(Fig. 5b). This was followed by a strengthening and more frequent southward migrations of the jet at the end of the twentieth century, coinciding with a transition toward $\mathrm{EA}_{\mathrm{DI}}+$ winters during 1975-2000. This shift from $\mathrm{EA}_{\mathrm{DI}}-$ to $\mathrm{EA}_{\mathrm{DI}}+$ (Figs. 3e,f) is timely with the wellreported migration of the North Atlantic action centers (e.g., Jung et al. 2003; Vicente-Serrano and LópezMoreno 2008). Similar transitions have been recurrent in the last three centuries (e.g., from $\mathrm{NAO}_{\mathrm{DI}}+/ \mathrm{EA}_{\mathrm{DI}}{ }^{+}$ to $\mathrm{NAO}_{\mathrm{DI}}+/ \mathrm{EA}_{\mathrm{DI}}-$ at the beginning of the twentieth century, or from $\mathrm{NAO}_{\mathrm{DI}}-/ \mathrm{EA}_{\mathrm{DI}}+$ to $\mathrm{NAO}_{\mathrm{DI}}-/ \mathrm{EA}_{\mathrm{DI}}-$ in the mid-nineteenth century). Therefore, our results stress that long-lasting anomalies (e.g., shifts) in the North Atlantic action centers can to a large extent be explained by different combinations of these indices and have occurred frequently in the last three centuries.

\section{Summary and discussion}

We present an almost continuous observational-based record of winter NAO, EA, and North Atlantic jet stream estimates for the last 330 years. These are the longest observational times series of the North Atlantic atmospheric circulation currently available and constitute a valuable tool to study the European climate variability beyond the industrial era, when only proxybased NAO indices can be found. They are obtained from the DIs (Mellado-Cano et al. 2019, manuscript submitted to Climate Dyn.), which measure the persistence of the wind in the four cardinal directions based on wind direction observations over the English Channel. This strategic area (at the exit zone of the jet stream) and the dynamical links between wind persistence and pressure gradients make the DIs optimum indicators of the circulation signatures on larger spatial scales and surface climate anomalies over large areas of Europe, particularly when considered altogether (Mellado-Cano et al. 2019, manuscript submitted to Climate Dyn.).

Our indices are significantly correlated with traditional NAO and EA series, with comparable skill to that obtained between some instrumental indices (particularly of the EA), also capturing their main signatures on European temperature and precipitation and outstanding periods of the instrumental record. The combined influence of NAO and EA on the Euro-Atlantic climate variability is addressed for the twentieth century by partitioning the NAO/EA phase space into four groups of winters. When both indices are in the same phase the southern action center extends toward Europe, while winters of opposite phases are characterized by the westward retreat of the southern node. Therefore, in addition to the NAO, we evidence an important role of EA in modulating the geographical location of the North Atlantic action centers (Azores high and Icelandic low). Our results demonstrate that the joint effects of the NAO and EA cause European surface climate anomalies that can substantially differ from their canonical signatures. Although the sign of the temperature responses is largely determined by the NAO, the EA modulates the spatial pattern of the anomalies (magnitude and location). Precipitation responses are more sensitive to the concomitant state of the EA and $\mathrm{NAO}$, and there are regions where the EA can dampen and even reverse the NAO-related precipitation signal. For example, when both indices act together, the canonical NAO precipitation signal in western Mediterranean is mainly confined to winters with an out-of-phase EA, but it weakens when EA is in phase with the NAO because of an eastward shift of the precipitation response toward eastern Mediterranean. This has implications for the robustness of some widely reported fingerprints of the NAO and previous proxy-based reconstructions.

Furthermore, our results indicate that winter NAO and EA have significant complementary fingerprints in the North Atlantic jet stream on seasonal time scales, extending previous studies based on daily diagnostics (e.g., Woollings et al. 2010). The jet speed is more affected by the NAO, with the EA acting on the same direction, while NAO and EA are of comparable importance but have opposite effects in the jet latitude. As such, the largest departures in jet speed (latitude) tend to occur in winters with equal signed (opposite) phases of NAO and EA. Using historical (1960-2000) model simulations, Woollings and Blackburn (2012) found that meridional shifts of the jet are largely due to the NAO, while NAO and EA are of roughly equal importance in describing jet speed anomalies. These discrepancies with our results could be due to model biases in the jet, differences between our indices and those considered therein and/or nonstationary influences of NAO and EA on the jet.

The evolution of the NAO and EA indices and their interactions through the last three centuries provide evidences of the dynamics behind some anomalous periods and extreme episodes and unveil substantial interannual to centennial variability in the North Atlantic jet stream. Recent changes in the Euro-Atlantic circulation such as the displacement of the North Atlantic action centers during the last decades of the twentieth century agree with temporary transitions between preferred NAO/EA states on decadal time scales. Similar transitions have been recurrent in the last three centuries, explaining some disagreements between historical NAO indices and pointing the EA as a potential source of nonstationary signatures of the NAO. This has implications for NAO reconstructions based on proxy records, whose climatic signals are 
calibrated against the NAO alone, therefore assuming stationary relationships. As climate anomalies are often affected by the concomitant state of NAO and EA (even in canonical spots of the NAO), the blurring effect of EA can lead to weak and sometimes misleading NAO-proxy relationships (Sánchez-López et al. 2016), affecting the skill of the NAO reconstruction. For example, when acting together, the Greenland cooling (warming) attributed to $\mathrm{NAO}+(\mathrm{NAO}-)$ is largely restricted to $\mathrm{EA}-(\mathrm{EA}+)$ phases. In addition, the precipitation NAO signal identified in Iberian and the Atlas proxies is related to winters with an out-of-phase EA, while over Turkey, precipitation responses are only relevant when both indices are in the same phase. This problem can be partially circumvented by performing reconstructions that rely on proxies from regions where the conflicting interferences of NAO and EA can be compensated. Notwithstanding, improved calibration and reconstructions of the atmospheric circulation would be better obtained by considering the joint effects of these indices. This is supported by the fact that nearly half of the winters in the last three centuries were dominated by the EA, meaning that a proper characterization of the Euro-Atlantic atmospheric circulation cannot be achieved by the NAO alone.

Our results also stress the need of additional efforts to delve further into the past evolution of the EA (in addition to that of the NAO). In this sense, a significant step forward could be achieved by fully integrating marine observations with instrumental series on land, thus yielding improved sea level pressure reconstructions and spatially coherent patterns that allow more detailed insights into the past climate variability than regional indices. This would also make it possible to better pin down the long-term variability of the North Atlantic jet stream. Further studies are also required to disentangle its internal variability from externally forced responses. This idea gains special relevance in the context of the ongoing climate change and the large uncertainty in future climate change projections of the jet stream (e.g., Peings et al. 2018). Although jet speed and latitude are herein inferred from linear regression models with different skills, our results indicate that they are largely independent and may thus respond differently to changes in external forcings (including rising concentrations of greenhouse gases). Therefore, prospective studies should also distinguish future changes in jet speed and latitude, which have different impacts on European regional climates.

Acknowledgments. This work is a contribution to UID/GEO/50019/2019-Instituto Dom Luiz. Javier Mellado-Cano was supported by the Portuguese Science Foundation (FCT) through the $\mathrm{PhD}$ fellowship $\mathrm{PD} / \mathrm{BD} /$ 106028/2014, and by the Spanish Ministry of Economy and
Competitiveness through the PALEOSTRAT (CGL201569699-R) project through the contract PAII18/19/2/2019/14. Ricardo M. Trigo and Armand Hernández were founded through the HOLMODRIVE (PTDC/CTA-GEO/29029/ 2018) project. Ricardo M. Trigo was also funded by project INDECIS, part of the European Research Area for Climate Services (ERA4CS). The authors are particularly thankful to the NOAA for providing the ICOADS 3.0 dataset (http://icoads.noaa.gov/). Temperature data and precipitation were provided by the CRU (http:// www.cru.uea.ac.uk) and the GPCC (http://gpcc.dwd.de), respectively. Support for the ERA-20C dataset is provided by the European Centre for Medium-Range Weather Forecasts (ECMWF). We thank two anonymous reviewers for their valuable comments, which helped to improve the manuscript.

\section{REFERENCES}

Appenzeller, C., T. F. Stocker, and M. Anklin, 1998: North Atlantic Oscillation dynamics recorded in Greenland ice cores. Science, 282, 446-449, https://doi.org/10.1126/science.282.5388.446.

Barnston, A. G., and R. E. Livezey, 1987: Classification, seasonality and persistence of low-frequency atmospheric circulation patterns. Mon. Wea. Rev., 115, 1083-1126, https://doi.org/ 10.1175/1520-0493(1987)115<1083:CSAPOL>2.0.CO;2.

Barriopedro, D., D. Gallego, M. C. Álvarez-Castro, R. GarcíaHerrera, D. Wheeler, C. Peña-Ortiz, and S. M. Barbosa, 2014: Witnessing North Atlantic westerlies variability from ships' logbooks (1685-2008). Climate Dyn., 43, 939-955, https:// doi.org/10.1007/s00382-013-1957-8.

Bastos, A., and Coauthors, 2016: European $\mathrm{CO}_{2}$ sink influenced by NAO and east-Atlantic pattern coupling. Nat. Commun., 7, 10315, https://doi.org/10.1038/ncomms10315.

Briffa, K. R., P. D. Jones, J. R. Pilcher, and M. K. Hughes, 1988: Reconstructing summer temperatures in northern Fennoscandinavia back to A.D. 1700 using tree-ring data from Scots pine. Arctic Alp. Res., 20, 385-394, https://doi.org/10.2307/1551336.

Bruce, P., and A. Bruce, 2017: Practical Statistics for Data Scientists: 50 Essential Concepts. O'Reilly Media, 318 pp.

Comas-Bru, L., and F. McDermott, 2014: Impacts of the EA and SCA patterns on the European twentieth century NAOwinter climate relationship. Quart. J. Roy. Meteor. Soc., 140, 354-363, https://doi.org/10.1002/qj.2158.

— modes: Revised monthly indices for the east Atlantic and the Scandinavian patterns beyond the 20th century. Earth Syst. Sci. Data, https://doi.org/10.5194/essd-10-2329-2018.

Cook, E. R., R. D. D. Arrigo, and K. R. Briffa, 1998: The North Atlantic Oscillation and its expression in circum-Atlantic treering chronologies from North America and Europe. Holocene, 8, 9-17, https://doi.org/10.1191/095968398677793725.

—, D. M. Meko, D. W. Stahle, and M. K. Cleaveland, 1999: Drought reconstructions for the continental United States. J. Climate, 12, 1145-116, https://doi.org/10.1175/15200442(1999)012<1145:DRFTCU>2.0.CO;2.

Cornes, R. C., P. D. Jones, K. R. Briffa, and T. J. Osborn, 2013: Estimates of the North Atlantic Oscillation back to 1692 using a Paris-London westerly index. Int. J. Climatol., 33, 228 248, https://doi.org/10.1002/joc.3416. 
D'Arrigo, R., R. Seager, J. E. Smerdon, A. N. LeGrande, and E. R. Cook, 2011: The anomalous winter of 1783-1784: Was the Laki eruption or an analog of the 2009-2010 winter to blame? Geophys. Res. Lett., 38, L05706, https://doi.org/10.1029/2011gl046696.

Davini, P., C. Cagnazzo, R. Neale, and J. Tribbia, 2012: Coupling between Greenland blocking and the North Atlantic Oscillation pattern. Geophys. Res. Lett., 39, L14701, https://doi.org/ 10.1029/2012GL052315.

Domínguez-Castro, F., J. I. Santisteban, M. Barriendos, and R. Mediavilla, 2008: Reconstruction of drought episodes for central Spain from rogation ceremonies recorded at Toledo Cathedral from 1506 to 1900: A methodological approach. Global Planet. Change, 63, 230-242, https://doi.org/10.1016/ j.gloplacha.2008.06.002.

Folland, C. K., J. Knight, H. W. Linderholm, D. Fereday, S. Ineson, and J. W. Hurrell, 2009: The summer North Atlantic Oscillation: Past, present, and future. J. Climate, 22, 1082-1103, https://doi.org/10.1175/2008JCLI2459.1.

Gaetani, M., B. Pohl, H. Douville, and B. Fontaine, 2011: West African monsoon influence on the summer Euro-Atlantic circulation. Geophys. Res. Lett., 38, L09705, https://doi.org/ 10.1029/2011GL047150.

García-Herrera, R., and D. Barriopedro, 2018: Climate of the Mediterranean region. Oxford Research Encyclopedia of Climate Science, https://doi.org/10.1093/acrefore/9780190228620.013.509.

— - _ D. Gallego, J. Mellado-Cano, D. Wheeler, and C. Wilkinson, 2018: Understanding weather and climate of the last 300 years from ships' logbooks. Wiley Interdiscip. Rev.: Climate Change, 9, e544, https://doi.org/10.1002/wcc.544.

Greatbatch, R. J., G. Gollan, T. Jung, and T. Kunz, 2015: Tropical origin of the severe European winter of 1962/1963. Quart. J. Roy. Meteor. Soc., 141, 153-165, https://doi.org/10.1002/qj.2346.

Hanna, E., T. E. Cropper, R. J. Hall, and J. Cappelen, 2016: Greenland Blocking Index 1851-2015: A regional climate change signal. Int. J. Climatol., 36, 4847-4861, https://doi.org/ 10.1002/joc. 4673 .

Harris, I., P. D. Jones, T. J. Osborn, and D. H. Lister, 2014: Updated high-resolution grids of monthly climatic observations-The CRU TS3.10 dataset. Int. J. Climatol., 34, 623-642, https:// doi.org/10.1002/joc.3711.

Hernández, A., and Coauthors, 2015: Sensitivity of two Iberian lakes to North Atlantic atmospheric circulation modes. Climate Dyn., 45, 3403-3417, https://doi.org/10.1007/s00382-015-2547-8.

Hurrell, J. W., 1995: Decadal trends in the North Atlantic Oscillation and relationships to regional temperature and precipitation. Science, 269, 676-679, https://doi.org/10.1126/ science.269.5224.676.

_, Y. Kushnir, G. Ottersen, and M. Visbeck, 2003: An overview of the North Atlantic Oscillation. The North Atlantic Oscillation: Climatic Significance and Environmental Impact, Geophys. Monogr., Vol. 134, Amer. Geophys. Union, 1-35, https://doi.org/10.1029/134GM01.

Jacobeit, J., H. Wanner, J. Luterbacher, C. Beck, A. Philipp, and K. Sturm, 2003: Atmospheric circulation variability in the North-Atlantic-European area since the mid-seventeenth century. Climate Dyn., 20, 341-352, https://doi.org/10.1007/ s00382-002-0278-0.

Jerez, S., and R. M. Trigo, 2013: Time-scale and extent at which large-scale circulation modes determine the wind and solar potential in the Iberian Peninsula. Environ. Res. Lett., 8, 044035, https://doi.org/10.1088/1748-9326/8/4/044035.

Jones, P. D., T. Jonsson, and D. Wheeler, 1997: Extension to the North Atlantic oscillation using early instrumental pressure observations from Gibraltar and south-west Iceland. Int. J. Climatol., 17, 1433-1450, https://doi.org/10.1002/(SICI)10970088(19971115)17:13<1433::AID-JOC203>3.0.CO;2-P.

Jung, T., M. Hilmer, E. Ruprecht, S. Kleppek, S. Gulev, and O. Zolina, 2003: Characteristics of the recent eastward shift of interannual NAO variability. J. Climate, 16, 3371-3382, https:// doi.org/10.1175/1520-0442(2003)016<3371:COTRES > 2.0.CO;2.

Kalnay, E., and Coauthors, 1996: The NCEP/NCAR 40-Year Reanalysis Project. Bull. Amer. Meteor. Soc., 77, 437-471, https:// doi.org/10.1175/1520-0477(1996)077<0437:TNYRP>2.0.CO;2.

Luterbacher, J., and Coauthors, 2001: Extending North Atlantic oscillation reconstructions back to 1500. Atmos. Sci. Lett., 2 , 114-124, https://doi.org/10.1006/asle.2002.0047.

_ D. Dietrich, E. Xoplaki, M. Grosjean, and H. Wanner, 2004: European seasonal and annual temperature variability, trends, and extremes since 1500. Science, 303, 1499-1503, https:// doi.org/10.1126/science.1093877.

Mahlstein, I., R. W. Portmann, J. S. Daniel, S. Solomon, and R. Knutti, 2012: Perceptible changes in regional precipitation in a future climate. Geophys. Res. Lett., 39, L05701, https:// doi.org/10.1029/2011g1050738.

Mellado-Cano, J., D. Barriopedro, R. García-Herrera, R. M. Trigo, and M. C. Álvarez-Castro, 2018: Euro-Atlantic atmospheric circulation during the Late Maunder Minimum. J. Climate, 31, 3849-3863, https://doi.org/10.1175/JCLI-D-17-0261.1.

Moore, G. W. K., and I. A. Renfrew, 2012: Cold European winters: Interplay between the NAO and the East Atlantic mode. Atmos. Sci. Lett., 13, 1-8, https://doi.org/10.1002/ asl.356.

, R. S. Pickart, and I. A. Renfrew, 2011: Complexities in the climate of the subpolar North Atlantic: A case study from the winter of 2007. Quart. J. Roy. Meteor. Soc., 137, 757-767, https://doi.org/10.1002/qj.778.

_ I. A. Renfrew, and R. S. Pickart, 2013: Multidecadal mobility of the North Atlantic Oscillation. J. Climate, 26, 2453-2466, https://doi.org/10.1175/JCLI-D-12-00023.1.

Ortega, P., F. Lehner, D. Swingedouw, V. Masson-Delmotte, C. Raible, M. Casado, and P. Yiou, 2015: A model-tested North Atlantic Oscillation reconstruction for the past millennium. Nature, 523, 71-74, https://doi.org/10.1038/ nature14518.

Pauling, A., J. Luterbacher, C. Casty, and H. Wanner, 2006: Five hundred years of gridded high-resolution precipitation reconstructions over Europe and the connection to large-scale circulation. Climate Dyn., 26, 387-405, https://doi.org/10.1007/ s00382-005-0090-8.

Peings, Y., J. Cattiaux, S. Vavrus, and G. Magnusdottir, 2018: Projected squeezing of the wintertime North-Atlantic jet. Environ. Res. Lett., 13, 074016, https://doi.org/10.1088/17489326/aacc79.

Pinto, J. G., and C. C. Raible, 2012: Past and recent changes in the North Atlantic oscillation. Wiley Interdiscip. Rev.: Climate Change, 3, 79-90, https://doi.org/10.1002/wcc.150.

- U. U. Ulbrich, G. C. Leckebusch, T. Spangehl, M. Reyers, and S. Zacharias, 2007: Changes in storm track and cyclone activity in three SRES ensemble experiments with the ECHAM5/ MPI-OM1 GCM. Climate Dyn., 29, 195-210, https://doi.org/ 10.1007/s00382-007-0230-4.

Poli, P., and Coauthors, 2016: ERA-20C: An atmospheric reanalysis of the twentieth century. J. Climate, 29, 4083-4097, https://doi.org/10.1175/JCLI-D-15-0556.1.

Raible, C. C., F. Lehner, J. F. Gonzalez-Rouco, and L. FernandezDonado, 2014: Changing correlation structures of the Northern 
Hemisphere atmospheric circulation from 1000 to 2100 AD. Climate Past, 10, 537-550, https://doi.org/10.5194/cp-10-5372014.

Röthlisberger, M., S. Pfahl, and O. Martius, 2016: Regional-scale jet waviness modulates the occurrence of midlatitude weather extremes. Geophys. Res. Lett., 43, 10 989-10 997, https:// doi.org/10.1002/2016GL070944.

Sáenz, J., J. Zubillaga, and C. Rodriguez-Puebla, 2001: Interannual variability of winter precipitation in northern Iberian Peninsula. Int. J. Climatol., 21, 1503-1513, https://doi.org/10.1002/ joc.699.

Sánchez-López, G., and Coauthors, 2016: Climate reconstruction for the last two millennia in central Iberia: The role of east Atlantic (EA), North Atlantic Oscillation (NAO) and their interplay over the Iberian Peninsula. Quat. Sci. Rev., 149, 135150, https://doi.org/10.1016/j.quascirev.2016.07.021.

Santos, J. A., T. Woollings, and J. G. Pinto, 2013: Are the winters 2010 and 2012 archetypes exhibiting extreme opposite behavior of the North Atlantic jet stream? Mon. Wea. Rev., 141, 3626-3640, https://doi.org/10.1175/MWR-D-13-00024.1.

Schamm, K., M. Ziese, A. Becker, P. Finger, A. Meyer-Christoffer, U. Schneider, M. Schröder, and P. Stender, 2014: Global gridded precipitation over land: A description of the new GPCC First Guess Daily product. Earth Syst. Sci. Data, 6, 4960, https://doi.org/10.5194/essd-6-49-2014.

Schmutz, C., J. Luterbacher, D. Gyalistras, E. Xoplaki, and H. Wanner, 2000: Can we trust proxy-based NAO index reconstructions? Geophys. Res. Lett., 27, 1135-1138, https:// doi.org/10.1029/1999GL011045.

Schultz, J., B. Christoph, G. Menz, B. Neuwirth, C. Ohlwein, and A. Philipp, 2015: Sensitivity of proxies on non-linear interactions in the climate system. Sci. Rep., 5, 18560, https:// doi.org/10.1038/srep18560.

Sjolte, J., C. Sturm, F. Adolphi, B. M. Vinther, M. Werner, G. Lohmann, and R. Muscheler, 2018: Solar and volcanic forcing of North Atlantic climate inferred from a processbased reconstruction. Climate Past, 14, 1179-1194, https:// doi.org/10.5194/cp-14-1179-2018.

Slonosky, V., and P. Yiou, 2001: The North Atlantic Oscillation and its relationship with near surface temperature. Geophys. Res. Lett., 28, 807-810, https://doi.org/10.1029/2000gl012063.

Sousa, P. M., R. M. Trigo, P. Aizpurua, R. Nieto, L. Gimeno, and R. Garcia-Herrera, 2011: Trends and extremes of drought indices throughout the 20th century in the Mediterranean. Nat. Hazards Earth Syst. Sci., 11, 33-51, https://doi.org/ 10.5194/nhess-11-33-2011.

Toreti, A., E. Xoplaki, D. Maraun, F. G. Kuglitsch, H. Wanner, and J. Luterbacher, 2010: Characterisation of extreme winter precipitation in Mediterranean coastal sites and associated anomalous atmospheric circulation patterns. Nat. Hazards Earth Syst. Sci., 10, 1037-1050, https://doi.org/10.5194/nhess10-1037-2010.

Trigo, R. M., T. J. Osborn, and J. M. Corte-Real, 2002: The North Atlantic Oscillation influence on Europe: Climate impacts and associated physical mechanisms. Climate Res., 20, 9-17, https://doi.org/10.3354/cr020009.

_- M. A. Valente, I. F. Trigo, M. Miranda, A. M. Ramos, D. Paredes, and R. García-Herrera, 2008: North Atlantic wind and cyclone trends and their impact in the European precipitation and Atlantic significant wave height. Ann N. Y. Acad. Sci., 1146, 212-234, https://doi.org/10.1196/ annals.1446.014.

Trouet, V., J. Esper, N. E. Graham, A. Baker, J. Scourse, and D. Frank, 2009: Persistent positive North Atlantic Oscillation mode dominated the Medieval Climate Anomaly. Science, 324, 78-80, https://doi.org/10.1126/science.1166349.

Vicente-Serrano, S. M., and J. I. López-Moreno, 2008: Nonstationary influence of the North Atlantic Oscillation on European precipitation. J. Geophys. Res., 113, D20120, https:// doi.org/10.1029/2008JD010382.

— , and Coauthors, 2018: Global assessment of the Standardized Evapotranspiration Deficit Index (SEDI) for drought analysis and monitoring. J. Climate, 31, 5371-5393, https://doi.org/ 10.1175/JCLI-D-17-0775.1.

Visbeck, M., J. W. Hurrell, L. Polvani, and H. Cullen, 2001: The North Atlantic oscillation: Past, present, and future. Proc. Natl. Acad. Sci. USA, 98, 12 876-12877, https://doi.org/ 10.1073/pnas.231391598.

Wallace, J. M., and D. S. Gutzler, 1981: Teleconnections in the geopotential height field during the Northern Hemisphere winter. Mon. Wea. Rev., 109, 784-812, https://doi.org/10.1175/ 1520-0493(1981)109<0784:TITGHF>2.0.CO;2.

Wilks, D. S., 2011: Statistical Methods in the Atmospheric Sciences. 3rd ed. Elsevier, 676 pp.

Woollings, T., and M. Blackburn, 2012: The North Atlantic jet stream under climate change, as described by the NAO and EA patterns. J. Climate, 25, 886-902, https://doi.org/10.1175/ JCLI-D-11-00087.1.

_ A. Hannachi, and B. Hoskins, 2010: Variability of the North Atlantic eddy-driven jet stream. Quart. J. Roy. Meteor. Soc., 136, 856-868, https://doi.org/10.1002/qj.625.

, and Coauthors, 2018: Daily to decadal modulation of jet variability. J. Climate, 31, 1297-1314, https://doi.org/10.1175/ JCLI-D-17-0286.1.

Zappa, G., and T. G. Shepherd, 2017: Storylines of atmospheric circulation change for European regional climate impact assessment. J. Climate, 30, 6561-6577, https://doi.org/10.1175/ JCLI-D-16-0807.1. 